\title{
Comprehensive analysis of marker gene detection and computed tomography for the diagnosis of human lung cancer
}

\author{
MIN CHENG ${ }^{1}$, XIAOSONG SUN ${ }^{2}$, GUIFENG LIU $^{1}$, KAILIANG CHENG ${ }^{1}$, \\ ZHONGWEN LV ${ }^{1}$, CHANGJIANG SUN ${ }^{1}$, DIANHUI XIU ${ }^{1}$ and LIN LIU ${ }^{1}$ \\ ${ }^{1}$ Department of Radiology, Jilin University, China Japan Union Hospital, Changchun, Jilin 130033; \\ ${ }^{2}$ Department of Head and Neck Surgery, Jilin Cancer Hospital, Changchun, Jilin 130000, P.R. China
}

Received October 2, 2017; Accepted March 9, 2018

DOI: $10.3892 / \mathrm{ol} .2018 .9211$

\begin{abstract}
Non-small cell lung cancer (NSCLC) is one of leading causes of cancer-associated mortality, with a high number of cases caused by metastasis. The early diagnosis of cancer contributes to the successful treatment of patients with lung cancer. The aim of the present study was to analyze the efficacy of marker gene detection and computed tomography (CT) in diagnosing human lung cancer. Lung cancer marker genes, including carcinoembryonic antigen (CEA), cancer antigen 125 (CA125), tissue polypeptide antigen (TPA), pro-gastrin-releasing peptide (ProGRB), cytokeratin fragment 21-1 (Cyfra21-1) and neuron-specific enolase (NSE), were analyzed in patients with lung cancer. The tumor size was evaluated using $\mathrm{CT}$, and the association between lung serum levels of marker gene protein expression and tumor size was investigated. A total of 328 patients with lung cancer were identified, including 204 adenocarcinoma, 75 large cell carcinoma and 49 squamous cell carcinoma cases. All patients were indicated to have a high serum level of CEA, CA125, TPA, ProGRB, Cyfra21-1 and NSE, compared with the normal range. Immunohistochemistry demonstrated higher expression levels of CEA, CA125, TPA, ProGRB, Cyfra21-1 and NSE in lung tumor tissues, compared with the normal range. Results indicated that $\mathrm{CT}$ was able to diagnose tumor size for patients with lung cancer. The CEA and CA125 expression levels were associated with CT-diagnosed adenocarcinoma tumor size. Large cell carcinoma tumor size was associated with serum levels of CEA, TPA and ProGRB. Results indicated that Cyfra21-1 and NSE were associated with the squamous cell carcinoma cases, as demonstrated using CT. In conclusion, these results indicated that comprehensive analysis of marker gene detection and CT results may be used to diagnose human lung cancer.
\end{abstract}

Correspondence to: Dr Dianhui Xiu or Professor Lin Liu, Department of Radiology, Jilin University, China Japan Union Hospital, 126 Xiantai Street, Changchun, Jilin 130033, P.R. China E-mail: dianhuixiuprof@163.com

E-mail: liuliudoc@163.com

Key words: gene detection, computed tomography, lung cancer, tumor size

\section{Introduction}

Non-small cell lung cancer (NSCLC) is one of the most common types of human cancer, and makes up $>80 \%$ of all lung cancer cases $(1,2)$. Data analyses indicate that the 5 -year survival rate is $<5 \%$ for the majority of patients with NSCLC who have suffered from distant metastasis (3). NSCLC includes adenocarcinoma, large cell carcinoma and squamous cell carcinoma (4-6). Although various strategies exist for the treatment of NSCLC, the survival rate remains poor for affected patients (7); therefore an early diagnosis of NSCLC is beneficial for patients with cancer, so that they can receive the most appropriate therapeutic regimens.

An early diagnosis enables early treatment of lung cancer (8-10). Detection of carcinoembryonic antigen (CEA) in the serum is a sensitive panel for the potential molecular diagnosis of NSCLC (11). Expression of cancer antigen 125 (CA125) is associated with cisplatin susceptibility in human lung cancer cells, which may aid the diagnostic and therapeutic approaches (12). A previous study indicated that tissue polypeptide antigen (TPA) and cytokeratin fragment 21-1 (Cyfra21-1) are serum markers in patients with NSCLC that may be beneficial for the recognition of tumor relapse (13). In addition, pro-gastrin-releasing peptide (ProGRB) is a valuable marker with a high specificity for the diagnosis of lung cancer, with a similar diagnostic accuracy to pathological diagnosis (14). Furthermore, neuron-specific enolase (NSE) is a potential target in the diagnosis and treatment of lung cancer (15). These data indicate that expression levels of CEA, CA125, TPA, ProGRB, Cyfra21-1 and NSE are associated with the progression of lung cancer.

The purpose of the present study was to analyze the efficacy of marker gene detection and computed tomography (CT) in diagnosing human lung cancer. The association between lung cancer marker genes (CEA, CA125, TPA, ProGRB and cCyfra21-1) and tumor size in patients with lung cancer was also analyzed.

\section{Materials and methods}

Ethics statement. The clinical study design was approved by the Ethics Committee of the China Japan Union Hospital (Changchun, China; approval no. 20130701XA) and all 
patients provided written informed consent prior to the examinations.

Patients and healthy individuals. A total of 328 patients with NSCLC (186 males and 142 females; median age, 57 years old) and 328 healthy individuals (168 males and 160 females; median age, 57 years old) were enrolled between July 2013 and May 2017 at the China Japan Union Hospital. All patients with NSCLC who received any chemotherapy or radiotherapy prior to surgery were excluded from the study. All subjects in the present study underwent CT diagnosis (16). All subjects in the present study underwent imaging with a trimodality CT system. The characteristics of the patients with NSCLC are summarized in Table I.

CT scan protocol. The CT system consisted of a full-ring time-of-flight 64-slice positron emission tomography (PET)/CT scanner (Discovery PET/CT 690 VCT; GE Healthcare, Chicago, IL, USA). The CT diagnosis system was used to analyze NSCLC tumor size using the preprogrammed setting. The preprogrammed setting was optimized, as described previously (17) to achieve the best image formation. The lungs in all patients underwent contrast-enhanced $\mathrm{CT}$ according to the manufacturer's protocols (Discovery PET/CT 690 VCT). The Tumor-Node-Metastasis (TNM) stage (seventh edition) (18) was assigned based on intraboard consensus decision.

Reverse transcription-quantitative polymerase chain reaction (RT-qPCR). Total RNA was extracted from cancer tissues using an RNAeasy Mini kit (Qiagen GmbH, Hilden, Germany). RNA was reverse transcribed to cDNA using SuperScript ${ }^{\mathrm{TM}}$ III One-Step RT-PCR System with Platinum ${ }^{\mathrm{TM}}$ Taq High Fidelity DNA Polymerase (Thermo Fisher Scientific, Inc.), according to manufacturer's protocol. All forward and reverse primers were synthesized by Invitrogen (Thermo Fisher Scientific, Inc.; Table II). The thermocycling conditions were as follows: Initial denaturation at $95^{\circ} \mathrm{C}$ for $1 \mathrm{~min}$, followed by 45 cycles of $95^{\circ} \mathrm{C}$ for $30 \mathrm{sec}, 56^{\circ} \mathrm{C}$ for $30 \mathrm{sec}$ and $72^{\circ} \mathrm{C}$ for $15 \mathrm{sec}$. The reaction volume $(50 \mu \mathrm{l})$ contained $50 \mathrm{ng}$ genomic cDNA, $200 \mu \mathrm{M}$ dNTPs, $200 \mu \mathrm{M}$ primers, 2.5 U Taq DNA polymerase (Thermo Fisher Scientific, Inc.) and 2.5 U SYBR ${ }^{\circledR}$-Green (Thermo Fisher Scientific, Inc.). Relative mRNA expression levels were calculated by the $2^{-\Delta \Delta \mathrm{Cq}}$ method (19).

ELISA. A total of $10 \mathrm{ml}$ blood samples were collected from all patients and serum was obtained from using centrifugation at $4,500 \mathrm{x} \mathrm{g}$ for $10 \mathrm{~min}$ at $4^{\circ} \mathrm{C}$. Serum levels of CEA (catalog no. EHCEA; Thermo Fisher Scientific, Inc., Waltham, MA, USA), CA125 (EHMUC16; Thermo Fisher Scientific, Inc.), TPA (BMS258-2; Thermo Fisher Scientific, Inc.), ProGRB (DY7847-05; Bio-Rad Laboratories, Inc., Hercules, CA, USA), Cyfra21-1 (EHCYF211; Thermo Fisher Scientific, Inc.) or NSE (DENL20; Bio-Rad Laboratories, Inc.) were detected in subjects using ELISA kits according to the manufacturer's protocols. Finally, the serum concentrations of CEA, CA125, TPA, ProGRB, Cyfra21-1 and NSE were measured using an enzyme microplate reader at $450 \mathrm{~nm}$ (Bio-Rad Laboratories, Inc.).

Immunohistochemistry staining. Cancer tissues from 328 patients who underwent surgery for NSCLC were collected
Table I. Characteristics of patients with NSCLC.

\begin{tabular}{lcc}
\hline Characteristics & NSCLC patients & Healthy patients \\
\hline Total no., $\mathrm{n}$ & 328 & 328 \\
Males, $\mathrm{n}$ & 186 & 168 \\
Females, $\mathrm{n}$ & 664 & 160 \\
Age range (mean), & $36-68(57)$ & $36-68(57)$ \\
$\quad$ years & &
\end{tabular}

NSCLC, non-small cell lung cancer.

in the present study. The 328 tissue samples were fixed used $10 \%$ paraformaldehyde for $15 \mathrm{~min}$ at $37^{\circ} \mathrm{C}$ and stained with hematoxylin and eosin for $30 \mathrm{~min}$ at $37^{\circ} \mathrm{C}$, and final pathological diagnoses were confirmed. Immunohistochemical analysis was used to identify expression levels of NSCLC tumor markers CEA, CA125, TPA, ProGRB, Cyfra21-1 and NSE. Paraffin-embedded tissue sections (4- $\mu \mathrm{m}$ thick) were prepared and dewaxed in xylene for $12 \mathrm{~h}$ at $37^{\circ} \mathrm{C}$, followed by rehydrating in a gradient concentration of ethanol (100, 95 and 85\%). The paraffin sections were immersed in $3 \% \mathrm{H}_{2} \mathrm{O}_{2}$ at room temperature for $5 \mathrm{~min}$ at $37^{\circ} \mathrm{C}$ and antigen retrieval was performed at $95^{\circ} \mathrm{C}$ for 30 min using antigen retrieval buffer $[10 \mathrm{mM}$ citrate acid, $0.05 \%$ Tween-20 (pH 6.0)]. Following incubation with PBS containing 10\% bovine serum albumin (Beijing Solarbio Science \& Technology Co., Ltd., Beijing, China) for $2 \mathrm{~h}$ at $37^{\circ} \mathrm{C}$, the tissue sections were incubated at $4^{\circ} \mathrm{C}$ overnight with the following anti-human antibodies: CEA (1:1,000; cat. no. ab133633; Abcam, Cambridge, UK), CA125 (1:1,000; cat. no. ab10033; Abcam), TPA (1:1,000; cat. no. ab157469; Abcam), ProGRB (1:1,000; cat. no. ab158593; Abcam), Cyfra21-1 (1:1,000; cat. no. ab125831; Abcam) or NSE (1:1,000; cat. no. ab79757; Abcam), followed by further incubation with horseradish peroxidase-conjugated $\operatorname{IgG}$ monoclonal antibody (cat. no. PV-6001, OriGene Technologies, Inc., Beijing, China) at $4^{\circ} \mathrm{C}$ overnight with diaminobenzidine-peroxidase substrate (Gene Tech, Biotechnology Co., Ltd., Shanghai, China. Slides were finally counterstained with hematoxylin for $2 \mathrm{~h}$ at $37^{\circ} \mathrm{C}$ and mounted with coverslips, and images were captured using a MicroChemi 4.2 instrument (Eastwin, Shenzen, China) at $\mathrm{x} 40$, magnification.

Regression analysis. The serum levels of CEA, CA125, TPA, ProGRB, Cyfra21-1 and NSE in the detective data $(Y)$ were analyzed by regression analysis in various tumor sizes in patients with NSCLC using the least square convergence (20). Serum levels of CEA, CA125, TPA, ProGRB, Cyfra21-1 and NSE were predicted according to tumor size. The predicted curve that results in the lowest sum of squares is the best fit using Spearman's rank correlation analysis. If the fit is robust, then the parameters of the observed curve may be inferred from those of the predicted curve.

Statistical analysis. All data are presented as the mean \pm standard error. All data were analyzed using SPSS Statistics (version 19.0; IBM Corp., Armonk, NY, USA). Student's t-test were used to make comparisons between groups. $\mathrm{P}<0.05$ was considered to indicate a statistically significant difference. 
Table II. Primer sequences for RT-qPCR.

Sequence

\begin{tabular}{|c|c|c|}
\hline Gene Name & Reverse & Forward \\
\hline CEA & 5'-CTTATTACTGCCAGCAAAGGAGTAGTT-3' & 5'-CAAAGCTCGCTCCGTCTGTAG-3' \\
\hline CA125 & 5'-TCATGAAGATCCTCACCGAG-3' & 5'-GCATCCTCTTCAGTTACGTCC-3' \\
\hline TPA & 5'-ATGACTTCCTACAGCTATCG-3' & 5'-AATGCTTTCTCCGCTCTG-3' \\
\hline ProGRB & 5'-CCCCTGGAAAGGGCTCAACAC-3' & 5'-TCCAACCCAGGTCCTTCCTAAAGTC-3' \\
\hline Cyfra21-1 & 5'-GAAGGAAACCGAGCCTATTCAC-3' & 5'-CCACAAGCATCAAACCACCA-3' \\
\hline NSE & 5'-TCATGAAGATCCTCACCGAG-3' & 5'-CTTCATCTTCTCCCGCAGAG-3' \\
\hline$\beta$-actin & 5'-CGGAGTCAACGGATTTGGTC-3' & 5'-AGCCTTCTCCATGGTCGTGA-3' \\
\hline
\end{tabular}

Table III. Serum levels of tumor markers in patients with NSCLC.

\begin{tabular}{lcc}
\hline Marker & $\begin{array}{c}\text { Healthy patients } \\
(\mathrm{ng} / \mathrm{ml})\end{array}$ & $\begin{array}{c}\text { NSCLC patients } \\
(\mathrm{ng} / \mathrm{ml})\end{array}$ \\
\hline CEA & $2.6 \pm 1.2$ & $53.4 \pm 12.5$ \\
CA125 & $3.0 \pm 2.4$ & $42.5 \pm 13.5$ \\
TPA & $3.8 \pm 1.6$ & $35.8 \pm 8.4$ \\
ProGRB & $4.7 \pm 1.4$ & $41.4 \pm 9.5$ \\
Cyfra21-1 & $5.0 \pm 1.5$ & $46.3 \pm 9.6$ \\
NSE & $6.2 \pm 2.3$ & $31.5 \pm 7.6$ \\
\hline
\end{tabular}

CEA, carcinoembryonic antigen; CA125, cancer antigen 125; TPA, tissue polypeptide antigen; ProGRB, pro-gastrin-releasing peptide; Cyfra21-1, cytokeratin fragment 21-1; NSE, neuron-specific enolase; NSCLC, non-small cell lung cancer. Values are presented as the mean \pm standard error

Table IV. Association between tumor marker expression levels and Tumor-Node-Metastasis stage.

\begin{tabular}{llll}
\hline Marker & T stage & N stage & M stage \\
\hline CEA & $31.2 \pm 10.4$ & $53.4 \pm 12.5$ & $65.8 \pm 15.7$ \\
CA125 & $22.4 \pm 10.8$ & $42.6 \pm 14.6$ & $56.6 \pm 16.2$ \\
TPA & $41.2 \pm 13.7$ & $55.6 \pm 16.8$ & $83.5 \pm 26.8$ \\
ProGRB & $26.8 \pm 10.8$ & $42.7 \pm 11.4$ & $58.6 \pm 15.7$ \\
Cyfra21-1 & $32.6 \pm 16.6$ & $58.4 \pm 17.0$ & $78.5 \pm 14.9$ \\
NSE & $23.6 \pm 8.5$ & $41.0 \pm 9.8$ & $56.6 \pm 13.5$
\end{tabular}

CEA, carcinoembryonic antigen; CA125, cancer antigen 125; TPA, tissue polypeptide antigen; ProGRB, pro-gastrin-releasing peptide; Cyfra21-1, cytokeratin fragment 21-1; NSE, neuron-specific enolase. Values are presented the mean \pm standard error. The values are relative to the normal range.

\section{Results}

Serum levels of tumor markers in patients with lung cancer. In the present study, the serum levels of tumor markers were
Table V. Tumor size and tumor type.

\begin{tabular}{lrc}
\hline Tumor type & $\mathrm{n}$ & Tumor size, $\mathrm{mm}$ \\
\hline Adenocarcinoma & 204 & $3.2-8.4$ \\
Large cell carcinoma & 75 & $4.0-12.5$ \\
Squamous cell carcinoma & 49 & $3.1-15.0$ \\
\hline
\end{tabular}

Table VI. Diagnostic efficacy of marker gene detection and CT in 328 cases.

\begin{tabular}{lc}
\hline Diagnosis method & $\mathrm{n}$ \\
\hline Marker gene detection & 270 \\
CT & 256 \\
Marker gene detection combined with CT & 320
\end{tabular}

CT, computed tomography.

analyzed in 328 patients with NSCLC and age-matched healthy volunteers. The results demonstrated that serum levels of CEA, CA125, TPA, ProGRB, Cyfra21-1 and NSE were increased in patients with NSCLC compared with those in the healthy volunteers (Table III). As presented in Table IV, serum tumor marker expression levels were associated with a poor TNM stage of NSCLC. These results indicated that tumor markers of CEA, CA125, TPA, ProGRB, Cyfra21-1 and NSE are associated with the progression of NSCLC.

Marker gene expression in NSCLC tissues. The expression of CEA, CA125, TPA, ProGRB, Cyfra21-1 and NSE marker genes was examined in NSCLC tissues. It was indicated that gene expression levels of CEA, CA125, TPA, ProGRB, Cyfra21-1 and NSE were upregulated in NSCLC tissues compared with those in the corresponding adjacent non-tumor tissues, as determined using the quantitative polymerase chain reaction (Fig. 1). Immunohistochemistry demonstrated that expression levels of CEA, CA125, TPA, ProGRB, Cyfra21-1 and NSE were notably upregulated in NSCLC tissues compared with those in the corresponding adjacent non-tumor tissues (Fig. 2). These results indicated that NSCLC tissues 


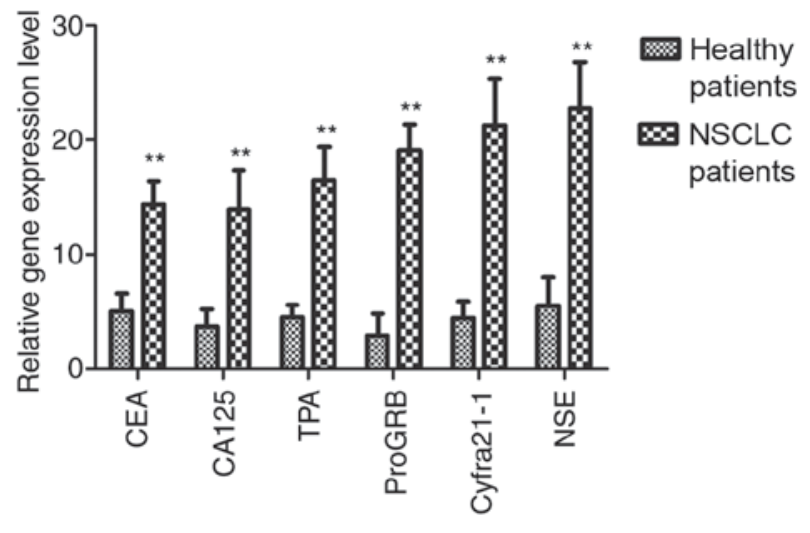

Figure 1. Gene expression levels of CEA, CA125, TPA, ProGRB, Cyfra21-1 and NSE in NSCLC tissues and adjacent non-tumor tissues, as determined using the quantitative polymerase chain reaction. ${ }^{* *} \mathrm{P}<0.01$ vs. healthy patients. CEA carcinoembryonic antigen; CA125, cancer antigen 125; TPA, tissue polypeptide antigen; ProGRB, pro-gastrin-releasing peptide; Cyfra21-1, cytokeratin fragment 21-1; NSE, neuron-specific enolase; NSCLC, non-small cell lung cancer.

exhibited increased expression levels of tumor markers compared with adjacent non-tumor tissues.

Tumor size detection by CT. The tumor size was determined by CT in the present study. As shown in Fig. 3, CT may be used to determine NSCLC tumor size. Among the patients, CT combined with gene expression identified 328 cases, including 204 adenocarcinoma cases, 75 large cell carcinoma cases and 49 squamous cell carcinoma cases determined by immunohistochemistry (Table V). These results indicated that CT combined with marker gene detection may be used to diagnose human NSCLC.

Analysis of the correlation between serum levels of marker gene proteins and tumor size. Spearman's rank correlation analysis was used to determine the correlation between serum levels of marker gene proteins and tumor size calculated using CT in a total of 328 patients with NSCLC. Spearman's rank correlation analysis demonstrated that CEA and CA125 serum levels were correlated with CT-diagnosed adenocarcinoma tumor size (Fig. 4A). Furthermore, large cell carcinoma tumor size was correlated with serum levels of CEA, TPA and ProGRB (Fig. 4B). Results indicated that Cyfra21-1 and NSE were associated with the squamous cell carcinoma cases diagnosed by $\mathrm{CT}$ (Fig. 4C). These results indicated that serum levels of marker gene proteins was associated with NSCLC size determined by $\mathrm{CT}$, which is beneficial for human NSCLC diagnosis.

Efficacy of comprehensive analysis of marker gene detection and CT for NSCLC diagnosis. Finally, the diagnostic efficacy of marker gene detection combined with CT was investigated in a total of 328 patients with NSCLC. It was demonstrated that comprehensive analysis of marker gene detection and CT was able to diagnose 320 patients with NSCLC, whereas CT alone diagnosed 256 patients with NSCLC and marker gene detection diagnosed 270 patients with NSCLC (Table VI). It was determined that only 8 patients with NSCLC could not be diagnosed using marker gene detection combined with $\mathrm{CT}$. These results indicated that comprehensive analysis of marker gene detection and CT is an efficient method for the diagnosis of patients with NSCLC.

\section{Discussion}

Lung cancer is a respiratory disease that is a major cause of cancer-associated mortality resulting from air contamination caused by industrial pollution globally (21). It has been indicated that the early diagnosis of patients with NSCLC is beneficial for the treatment of cancer (22). Serum tumor markers have been demonstrated to possess the ability to predict the efficacy of pemetrexed-based chemotherapy (23). In the present study, the efficacy of marker gene detection and CT for human lung cancer diagnosis was comprehensively analyzed. It was demonstrated that serum levels of CEA, CA125, TPA, ProGRB, Cyfra21-1 and NSE were significantly upregulated in patients with NSCLC. Results of the present study also indicated that marker gene expression levels were correlated with tumor size determined by CT for patients with NSCLC, according to Spearman's rank correlation analysis.

Currently, there are numerous cancer diagnostic methods, including ultrasound, X-ray screening, CT, magnetic resonance imaging and immunological detection (24-26). CT (fluorodeoxyglucose PET/CT) is frequently performed in hilar and mediastinal lymph node staging of NSCLC (27). The present study demonstrated that CT could approximately measure the NSCLC tumor size. A previous study indicated that PET/CT has become feasible for fast imaging and may be used for cancer staging in patients with a malignant condition (28). In addition, three-dimensional CT measurement may be useful for diagnosing nodal metastases (29). Notably, the present study determined that single CT diagnosis is insufficient in the diagnosis of patients with NSCLC.

The clinical value of a cancer diagnosis with tumor marker determination has been identified in lung cancer $(30,31)$. The present study demonstrated that tumor marker expression combined with CT is an efficient method of diagnosing patients with NSCLC. A previous study demonstrated the clinical value of CEA and CA125 to evaluate the relapse, metastasis and prognosis of patients with resectable NSCLC (32). The present study demonstrated that serum levels of CEA and CA125 levels were associated with CT-diagnosed adenocarcinoma tumor size. In addition, Wang et al (33) indicated that the serum concentrations of Cyfra21-1, NSE and CEA may be diagnostic indicators of meningeal carcinomatosis of lung cancer. Results of the present study indicated that Cyfra21-1 and NSE were associated with the squamous cell carcinoma cases. A previous meta-analysis indicated that the serum level of ProGRB is a promising biomarker for SCLC diagnosis (34). In the present study, it was indicated that the large cell carcinoma tumor size was associated with serum levels of CEA TPA and ProGRB. These data have identified that the tumor markers CEA, CA125, TPA, ProGRB, Cyfra21-1 and NSE are useful in determining tumor size.

In conclusion, the present study investigated the effects of tumor marker genes combined with $\mathrm{CT}$ in diagnosing patients with NSCLC. The results demonstrated that tumor markers CEA, CA125, TPA, ProGRB, Cyfra21-1 and NSE were significantly upregulated in NSCLC tissues. Furthermore, it was determined that tumor marker serum levels were associated with tumor size. 

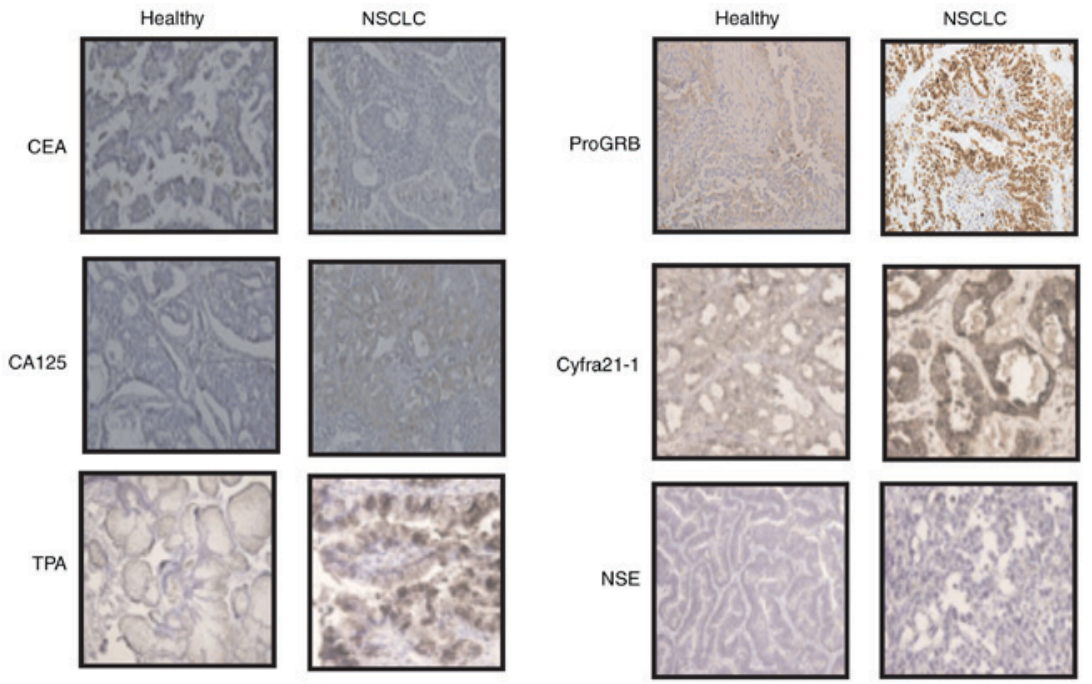

Figure 2. Expression levels of CEA, CA125, TPA, ProGRB, Cyfra21-1 and NSE in NSCLC tissues compared with those in corresponding adjacent non-tumor tissues, as determined by immunohistochemistry. Magnification, x40. CEA, carcinoembryonic antigen; CA125, cancer antigen 125; TPA, tissue polypeptide antigen; ProGRB, pro-gastrin-releasing peptide; Cyfra21-1, cytokeratin fragment 21-1; NSE, neuron-specific enolase; NSCLC, non-small cell lung cancer.
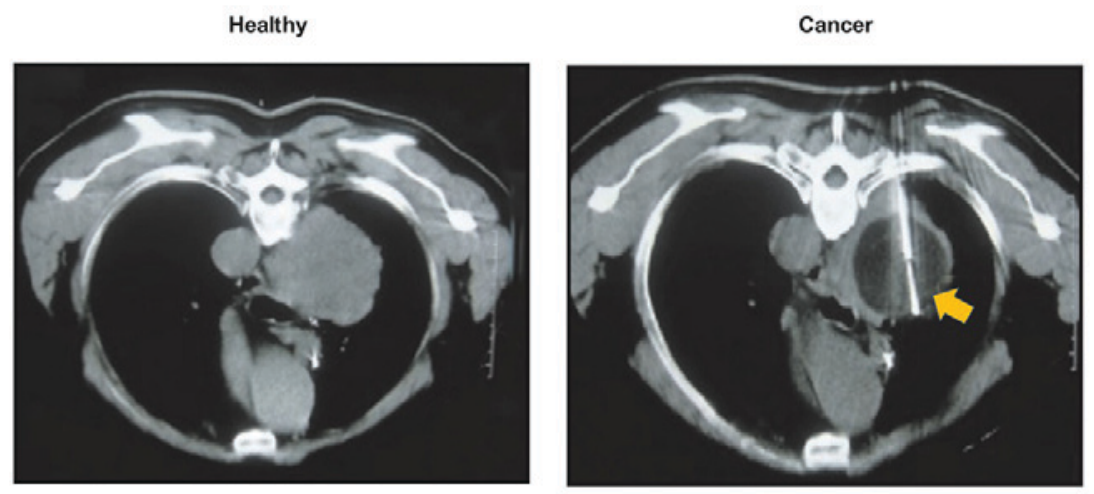

Figure 3. Representative images of tumor size diagnosed by computed tomography in patients with NSCLC. NSCLC, non-small cell lung cancer.
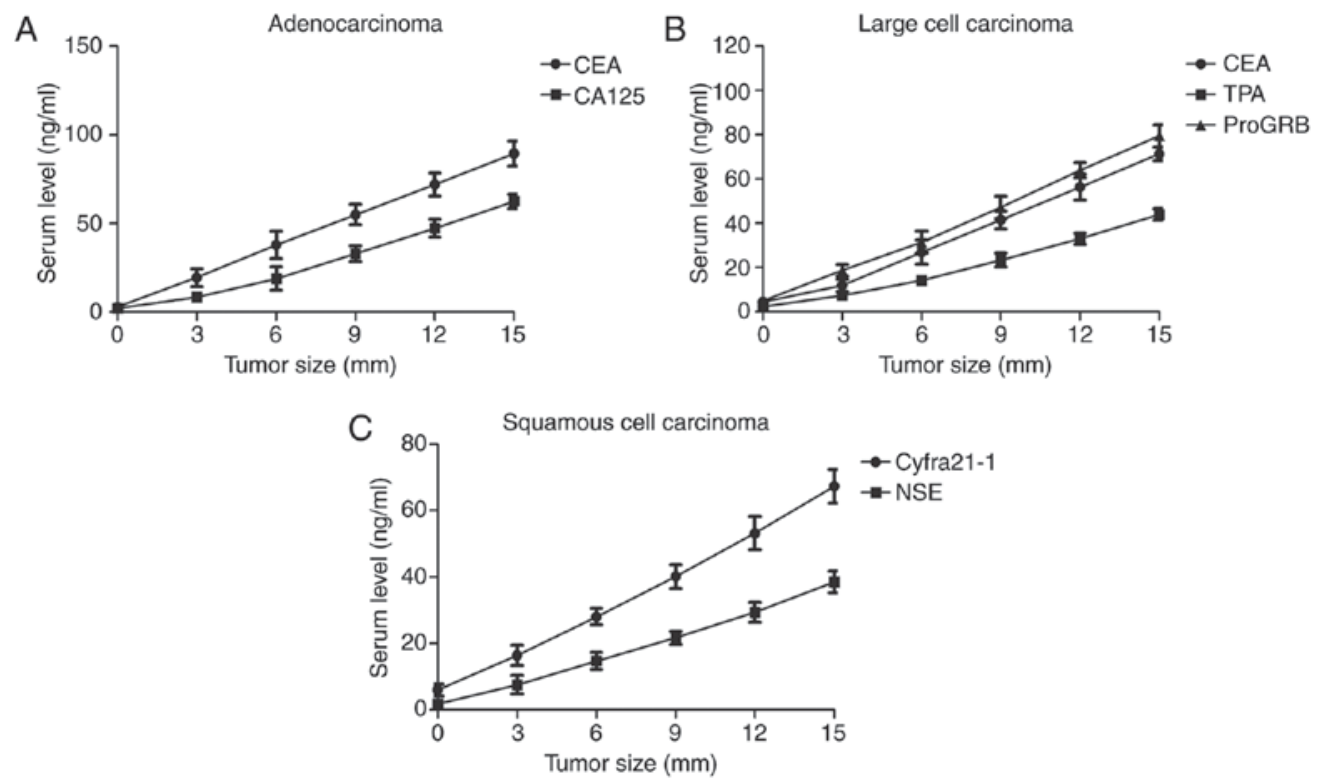

Figure 4. Analysis of the association between marker gene detection and tumor size. (A) Serum levels of CEA and CA125 are associated with CT-diagnosed adenocarcinoma tumor size. (B) Serum levels of CEA, TPA and ProGRB are associated with large cell carcinoma tumor size. (C) Serum levels of Cyfra21-1 and NSE are associated with CT-diagnosed squamous cell carcinoma tumor size. CEA, carcinoembryonic antigen; CA, cancer antigen 125; TPA, tissue polypeptide antigen; ProGRB, pro-gastrin-releasing peptide; Cyfra21-1, cytokeratin fragment 21-1; NSE, neuron-specific enolase; CT, computed tomography. 
Importantly, tumor markers combined with CT may contribute to diagnosing the progression and treatment of NSCLC cancer.

\section{Acknowledgements}

Not applicable.

\section{Funding}

No funding was received.

\section{Availability of data and materials}

The analyzed data sets generated during the study are available from the corresponding author on reasonable request.

\section{Authors' contributions}

MC conducted major experiments in this study. XS, GL, KC and ZL conducted a small number of experiments. CS and DX analyzed the experimental data in the present study. LL designed all experiments in the present study.

\section{Ethics approval and consent to participate}

The present study was approved by the Ethics Committee of the China Japan Union Hospital (Changchun, China; approval no. 20130701XA).

\section{Patient consent for publication}

All patients provided written informed consent prior to the examinations.

\section{Competing interests}

The authors declare that they have no competing interests.

\section{References}

1. Paleiron N, Bylicki O, André M, Rivière E, Grassin F, Robinet G and Chouaïd C: Targeted therapy for localized non-small-cell lung cancer: A review. Onco Targets Ther 9: 4099-4104, 2016.

2. Li SJ, Huang J, Zhou XD, Zhang WB, Lai YT and Che GW: Clinicopathological and prognostic significance of Oct-4 expression in patients with non-small cell lung cancer: A systematic review and meta-analysis. J Thorac Dis 8: 1587-1600, 2016.

3. Aokage K, Yoshida J, Hishida T, Tsuboi M, Saji H, Okada M, Suzuki K, Watanabe S and Asamura H: Limited resection for early-stage non-small cell lung cancer as function-preserving radical surgery: A review. Jpn J Clin Oncol 47: 7-11, 2017.

4. Brody H: Lung cancer. Nature 513: S1, 2014.

5. Moro-Sibilot D,Smit E, de Castro CarpeñoJ,Lesniewski-Kmak K, Aerts JG, Villatoro R, Kraaij K, Nacerddine K, Dyachkova Y, Smith KT, et al: Non-small cell lung cancer patients with brain metastases treated with first-line platinum-doublet chemotherapy: Analysis from the European FRAME study. Lung Cancer 90: 427-432, 2015.

6. Barnett SA, Downey RJ, Zheng J, Plourde G, Shen R, Chaft J, Akhurst T, Park BJ and Rusch VW: Utility of routine PET imaging to predict response and survival after induction therapy for non-small cell lung cancer. Ann Thorac Surg 101: 1052-1059, 2016

7. Loganadane G, Martinetti F, Mercier O, Krhili S, Riet FG, Mbagui R, To H, Le Péchoux C and Levy A: Stereotactic ablative radiotherapy for early stage non-small cell lung cancer: A critical literature review of predictive factors of relapse. Cancer Treat Rev 50: 240-246, 2016.
8. Kim JO, Davis F, Butts C and Winget M: Waiting time intervals for non-small cell lung cancer diagnosis and treatment in alberta: Quantification of intervals and identification of risk factors associated with delays. Clin Oncol (R Coll Radiol) 28: 750-759, 2016.

9. Zheng D and Chen H: Advances in liquid biopsy and its clinical application in the diagnosis and treatment of non-small cell lung cancer. Zhongguo Fei Ai Za Zhi 19: 394-398, 2016 (In Chinese).

10. Benitez-Majano S, Fowler H, Maringe C, Di Girolamo C and Rachet B: Deriving stage at diagnosis from multiple population-based sources: Colorectal and lung cancer in England. Br J Cancer 115: 391-400, 2016.

11. Sheu CC, Chang MY, Chang HC, Tsai JR, Lin SR, Chang SJ, Hwang JJ, Huang MS and Chong IW: Combined detection of CEA, CK-19 and c-met mRNAs in peripheral blood: A highly sensitive panel for potential molecular diagnosis of non-small cell lung cancer. Oncology 70: 203-211, 2006.

12. Chanvorachote P, Luanpitpong S, Chunhacha P, Promden W and Sriuranpong V: Expression of CA125 and cisplatin susceptibility of pleural effusion-derived human lung cancer cells from a Thai patient. Oncol Lett 4: 252-256, 2012.

13. Passowicz-Muszyńska E, Gisterek I, Marciniak M, Kornafel J, Kolodziej J and Jankowska R: Tumor markers TPA and Cyfra 21.1 in patients with non-small cell lung cancer after surgery and chemotherapy. Pol Merkur Lekarski 13: 294-297, 2002 (In Polish).

14. Tang JH, Zhang XL, Zhang ZH, Wang R, Zhang HM, Zhang ZL, Wang JH and Ren WD: Diagnostic value of tumor marker pro-gastrin-releasing peptide in patients with small cell lung cancer: A systematic review. Chin Med J (Engl) 124: 1563-1568, 2011.

15. Lazarev SM, Massard ZH, Reshetov AV, Nikolaev GV, Volgin GN, Osipov EV, Lomteva EIu, Nokhrin AV and Kakysheva OE: Role of biological tumor markers CEA, Cyfra-21, NSE, TU M2-PK in diagnosis and treatment of lung cancer. Vestn Khir Im I I Grek 169: 39-43, 2010 (In Russian).

16. Raz DJ, Wu GX, Consunji M, Nelson RA, Kim H, Sun CL, Sun V and Kim JY: The effect of primary care physician knowledge of lung cancer screening guidelines on perceptions and utilization of low-dose computed tomography. Clin Lung Cancer 19: 51-57, 2018.

17. Kawakami W, Takemura A, Yokoyama K, Nakajima K, Yokoyama S and Koshida K: The use of positron emission tomography/computed tomography imaging in radiation therapy: A phantom study for setting internal target volume of biological target volume. Radiat Oncol 10: 1, 2015.

18. Edge SB and Compton CC: The American joint committee on cancer: The 7th edition of the AJCC cancer staging manual and the future of TNM. Ann Surg Oncol 17: 1471-1474, 2010.

19. Livak KJ and Schmittgen TD: Analysis of relative gene expression data using real-time quantitative PCR and the 2(-Delta Delta C(T)) method. Methods 25: 402-408, 2001.

20. Hayes AF and Rockwood NJ: Regression-based statistical mediation and moderation analysis in clinical research: Observations, recommendations, and implementation. Behav Res Ther 98: 39-57, 2017.

21. Fenton-Ambrose L and Kazerooni EA: Preventative care: Lung-cancer screens now worth the cost. Nature 514: 35, 2014.

22. Herth F, Kirsch CM and Stoelben E: Diagnosis of non-small-cell lung carcinoma (NSCLC). Onkologie 29 (Suppl 2): S3-S6, 2006 (In German).

23. Fiala O, Pesek M, Finek J, Svaton M, Sorejs O, Bortlicek Z, Kucera R and Topolcan O: Prognostic significance of serum tumor markers in patients with advanced-stage NSCLC treated with pemetrexed-based chemotherapy. Anticancer Res 36: 461-466, 2016.

24. Barrio-Muñoz M1, Abad-Gairín C, Amengual-Guedán JM and Prats-López J: Diagnosis of prostate cancer by analyzing oxidative stress in human seminal plasma: Developing unsophisticated tools for noninvasive prostate cancer diagnosis. Eur J Cancer Prev 25: 518-523, 2016.

25. Yang L, Wang J, Li J, Zhang H, Guo S, Yan M, Zhu Z, Lan B, Ding $\mathrm{Y}, \mathrm{Xu} \mathrm{M}$, et al: Identification of serum biomarkers for gastric cancer diagnosis using a human proteome microarray. Mol Cell Proteomics 15: 614-623, 2016.

26. Zhu Y, Guo M, Zhang L, Xu T, Wang L and Xu G: Biomarker triplet NAMPT/VEGF/HER2 as a de novo detection panel for the diagnosis and prognosis of human breast cancer. Oncol Rep 35: 454-462, 2016.

27. Li S, Zheng Q, Ma Y, Wang Y, Feng Y, Zhao B and Yang Y: Implications of false negative and false positive diagnosis in lymph node staging of NSCLC by means of ${ }^{18} \mathrm{~F}-\mathrm{FDG}$ PET/CT. PLoS One 8: e78552, 2013. 
28. Kim HS, Lee KS, Ohno Y, van Beek EJ and Biederer J: PET/CT versus MRI for diagnosis, staging, and follow-up of lung cancer. J Magn Reson Imaging 42: 247-260, 2015.

29. Takahashi Y, Takashima S, Hakucho T, Miyake C, Morimoto D, Jiang BH, Numasaki H, Tomita Y,Nakanishi K and Higashiyama M Diagnosis of regional node metastases in lung cancer with computer-aided 3D measurement of the volume and CT-attenuation values of lymph nodes. Acad Radiol 20: 740-745, 2013.

30. Yang YJ, Cheng DY, Fang X and Li XX: The clinical diagnosis value of fibro-optic bronchoscope examination combined with tumor marker determination to lung cancer. Sichuan Da Xue Xue Bao Yi Xue Ban 38: 312-315, 2007 (In Chinese).

31. Shi GL, Hu XL, Yue SD and Song CX: The value of serum tumor marker in the diagnosis of lung cancer. Zhonghua Zhong Liu Za Zhi 27: 299-301, 2005.

32. Pollán M, Varela G, Torres A, de la Torre M, Ludeña MD, Ortega MD, Pac J, Freixenet J, Gómez G, Sebastián F, et al: Clinical value of p53, c-erbB-2, CEA and CA125 regarding relapse, metastasis and death in resectable non-small cell lung cancer. Int J Cancer 107: 781-790, 2003.
33. Wang P, Piao Y, Zhang X, Li W and Hao X: The concentration of CYFRA 21-1, NSE and CEA in cerebro-spinal fluid can be useful indicators for diagnosis of meningeal carcinomatosis of lung cancer. Cancer Biomark 13: 123-130, 2013.

34. Wang H and Qian J: Serum pro-gastrin-releasing peptide in diagnosis of small cell lung cancer: A meta-analysis. J Cancer Res Ther 12 (Suppl): C260-C263, 2016.

(i)(3) This work is licensed under a Creative Commons Attribution-NonCommercial-NoDerivatives 4.0 International (CC BY-NC-ND 4.0) License. 